\title{
Consumo televisivo de padres y niños y recepción de las representaciones de autoridad agenciadas por la televisión
}

\author{
Jakeline Duarte-Duarte ${ }^{1}$ \\ Juan Carlos Jurado-Jurado ${ }^{2}$
}

Recibido: 2015-09-05

Enviado a pares: 2015-09-14
Aprobado por pares: 2015-10-14

Aceptado: 2015-11-05

DOI: 10.5294/pacla.2016.19.2.11

\section{Para citar este artículo / To reference this article / Para citar este artigo}

Duarte-Duarte, J. \& Jurado-Jurado, J. C. (Junio de 2016). Consumo televisivo de padres y niños y recepción de las representaciones de autoridad agenciadas por la televisión.

Palabra Clave, 19(2), 607-629. D0I: 10.5294/pacla.2016.19.2.11

\section{Resumen}

El tema de este artículo se inscribe en el papel de la televisión como instancia cultural que dispone la formación de valores, actitudes y relaciones sociales de diverso orden. A la televisión se le ha adjudicado un lugar destacado en la aparente "crisis de autoridad" que viven las familias y la sociedad a causa de los contenidos que cuestionan la hegemonía de los adultos como figuras de autoridad. En esta perspectiva, se desarrolló una investigación de diseño mixto que contempló dentro de sus objetivos identificar el consumo televisivo de padres y niños entre 5 y 6 años y las representaciones de autoridad agenciadas por la televisión. Tal indagación se realizó mediante la aplicación de una encuesta a 81 padres de familia de diferentes estratos socioeconómicos de Medellín y Envigado, Colombia. Como conclusión, se destaca el consumo televisivo individualizado de los niños, el exiguo papel orientador de los padres en ello, la recepción de representaciones televisivas que expresan relaciones más simétricas entre padres e

Universidad de Antioquia. Colombia. jakeline.duarte@udea.edu.co

Universidad Eafit. Colombia. jjurado@eafit.edu.co 
hijos y la emergencia de nuevas figuras de poder propias del mundo delictivo, asumidas como figuras de autoridad.

\section{Palabras clave}

Televisión; padres; niños; familia; autoridad (Fuente: Tesauro de la Unesco).

\section{TV Consumption of Parents and Children and Receiving Representations from Television Authority Agencies}

\section{Abstract}

The topic of this article is part of the role of television as a cultural body that has the formation of values, attitudes and social relations at various levels. The television has been awarded an important role in the apparent "authority crisis" that families and society are living because of the content they question, and the hegemony of adults as authority figures. In this perspective, a mixed research design was developed that looked into their TV consumption objectives, identify parents and children between 5 and 6 years of age and representatives of television authority agencies. Such inquiry was conducted by applying a survey to 81 parents from different socioeconomic strata in Medellin and Envigado, Colombia. In conclusion, individualized television consumption by children stand out; a meager role in parental guidance, the reception of television representations expressing more symmetrical relations between parents and children and the emergence of new figures of their own power towards the criminal world, assumed as authoritative figures.

\section{Keywords}

Television; parents; children; family; authority (Source: Unesco Thesaurus). 


\section{Consumo televisivo de pais e filhos e recepção das representações de autoridade adquiridas pela televisão}

\section{Resumo}

Este artigo trata do papel da televisão como instância cultural que dispõe a formação de valores, atitudes e relações sociais de diversa natureza. À televisão, foi designado um lugar destacado na aparente "crise de autoridade" que as famílias e a sociedade vivem por causa dos conteúdos que questionam a hegemonia dos adultos como figuras de autoridade. Nessa perspectiva, desenvolveu-se uma pesquisa de metodologia mista que contemplou dentro de seus objetivos identificar o consumo televisivo de pais e filhos (estes entre 5 e 6 anos) e as representações de autoridade adquiridas pela televisão. Esse questionamento foi realizado mediante a aplicação de uma pesquisa de opinião a 81 pais de família de diferentes classes sociais de Medellín e Envigado (Colômbia). Como conclusão, destaca-se o consumo televisivo individualizado das crianças, o limitado papel orientador dos pais nisso, a recepção de representações televisivas que expressam relações mais simétricas entre pais e filhos e a urgência de novas figuras de poder próprias do mundo delitivo, assumidas como figuras de autoridade.

\section{Palavras-chave}

Televisão; pais; crianças; família; autoridade (Fonte: Tesauro da Unesco). 


\section{Introducción}

Las ciencias sociales y en particular los estudios de la comunicación han contribuido a desentrañar la naturaleza social y cultural de la acción social de "ver televisión” al asumirla como una práctica de "consumo", la cual es entendida por García Canclini como el conjunto de procesos socioculturales mediante los cuales se realiza la apropiación y el uso de productos televisivos (2006, p. 80). Por su parte, Silverstone (2004) plantea que el consumo es una actividad individual y colectiva de producción de significados que depende de la destrucción de bienes y servicios. Para el caso de la televisión, afirma que los sujetos pueden intervenir los productos televisivos a partir de los contextos sociales y culturales donde viven la experiencia mediática y que implican una dimensión material y simbólica, toda vez que ponen al sujeto en contacto con lo que la televisión le presenta como realidad visual objetiva y con la producción de sentido donde él tiene una parte activa. En el consumo mediatizado, el sujeto se apropia de objetos, imágenes e información pero no de manera homogénea, pues tiene la capacidad de someter el producto televisivo a un proceso hermenéutico que involucra su desconstrucción, revalorización y negociación (Silverstone, 2004, pp. 127-138). El hogar, con su profunda carga psíquica y emocional que lo caracteriza, es el espacio social por excelencia donde acontece el consumo televisivo en nuestras sociedades. Para Silverstone, los medios están en el centro de la "política doméstica", pues definen relaciones de poder e interacción entre quienes hacen del consumo televisivo una práctica propia que articula el "orden de vida cotidiano" al entrar en la vida familiar enmarcando y regulando el espacio tiempo doméstico (Silverstone, 2004, pp. 143-155).

El lugar de la televisión en el "orden de vida cotidiana" no es nada abstracto, sino que se concreta en rutinas, prácticas y estilos de vida, de modo que compromete la configuración de hábitos en los procesos de socialización mediante los cuales los sujetos son modelados socialmente según aprenden e incorporan creencias, valores y normas de la sociedad a la que pertenecen. Los hábitos están profundamente imbricados por las "rutinas", elementos básicos de la actividad cotidiana que implican la repetición de actividades realizadas de manera semejante día a día, sustentan sentimien- 
tos de estabilidad, confianza y seguridad en la vida colectiva y suponen una articulación entre "lo inconsciente y el registro reflexivo de una acción producida” (Giddens, 2003, p. 24).

Los hábitos de consumo televisivo de niños han sido ampliamente investigados desde diversas perspectivas teóricas y en diferentes latitudes del mundo occidental. Vale destacar que la mayoría de los estudios se centran en tópicos, como el número de horas de consumo, horarios, los géneros más vistos y su impacto en la subjetividad infantil, los espacios familiares de consumo y los actores sociales que ejercen la mediación del consumo de niños y jóvenes en el ámbito doméstico (De Oliveira, 2005; Torrecillas, 2012; Consejo Nacional de Televisión de Chile, 2011). Como hallazgo relevante de estos estudios consultados, se identificó un porcentaje elevado que presenta una significativa inclinación por indagar los "efectos y/o influencias" de la televisión en las actitudes y los comportamientos de los niños, sobre todo en mayores de 6 años, y menos interés en indagar desde posturas antropológicas y sociológicas, pese a los aportes de los estudios de recepción y de los estudios culturales, las corrientes más contemporáneas para el análisis de los medios de comunicación, que han superado aquel enfoque funcionalista. Muy pocas pesquisas asumen la primera infancia como televidencias importantes de indagar; para el caso colombiano se destaca el trabajo de Rodríguez (2012), quien indica que las investigaciones más recientes asumen a los niños como sujetos activos, que construyen significados de manera particular y orientan sus acciones y las de otros dependiendo de sus contextos culturales. En la misma perspectiva, se ubica la investigación desarrollada por el Ministerio de Cultura/Dirección de Cinematografía (2009) que hace énfasis en los procesos de subjetivación de los niños colombianos en los actuales ambientes mediáticos.

Asimismo, vale la pena hacer hincapié en que la literatura no arroja datos acerca de la forma como los contenidos televisivos disponen entre padres e hijos relaciones de poder, obediencia, la vivencia de las normas y castigos, la subordinación y las decisiones que comprometen distintas situaciones familiares. Es de aclarar que en aquellos estudios en los que se aborda explícita o tangencialmente la autoridad ha sido para evidenciar las 
prácticas mediadoras de los padres en el momento de regular el consumo televisivo de sus hijos, pero no las representaciones de autoridad agenciadas por los contenidos televisivos y su recepción en el medio familiar.

En el presente artículo, se exponen hallazgos parciales que dan cuentan de los principales hábitos de consumo televisivo de niños de 5 años de edad, reportados por sus padres, al igual que las rutinas de consumo de estos últimos y la manera como recepcionan las representaciones de autoridad agenciadas por la televisión.

\section{Metodología}

Los hallazgos que aquí se presentan corresponden a los resultados cuantitativos de la fase exploratoria de un estudio hermenéutico de diseño mixto desarrollado con 81 padres de familia de niños de 5 años de diferentes estratos socioeconómicos de Medellín y Envigado (Colombia). Tal fase se desarrolló a partir de la implementación de una encuesta ${ }^{3}$ dirigida a los padres de cuatro instituciones educativas privadas, de niños del grado de transición (preescolar). ${ }^{4}$ De los encuestados, 67 residen en Medellín y 14 en Envigado. De ellos, 64 son madres de familia y 17 padres, cuya edad promedio es de 34 y 37 años, respectivamente. El total de los datos cuantitativos recolectados en las encuestas fue sistematizado en el programa SPSS versión 19. El análisis estadístico fue de tipo descriptivo mediante distribución de frecuencias para cada una de las preguntas realizadas y se estableció una relación de categorías en función del estrato socioeconómico de los participantes.

3 La encuesta se estructuró a partir de las categorías hábitos de consumo televisivo y representaciones de autoridad agenciadas por la televisión, siendo esta última objeto de mayor indagación a partir de las siguientes subcategorías: normas, estrategias de corrección, afecto, género, situaciones de vida familiar, aportes de la televisión al manejo de la autoridad en la vida familiar, incorporación, negociación y resistencia frente a géneros televisivos y contexto sociocultural que explica la autoridad. Dado que los resultados de la encuesta solo aplicaron para quienes participaron en el estudio, no fue necesario definir el coeficiente de error y el porcentaje de confiabilidad; sin embargo, fue validada en su contenido por cinco expertos. Se hizo una prueba piloto con 18 padres de diferentes estratos socioeconómicos de manera que se ajustara la versión definitiva del instrumento.

4 En cuanto a las consideraciones éticas del estudio, se les solicitó a los padres firmar el consentimiento informado, que consiste en un documento que explicita los asuntos concernientes a los participantes respecto de los objetivos de la investigación, las técnicas de recolección, los compromisos que adquiere al vincularse voluntariamente a la investigación, los riesgos potenciales de su participación y la de sus hijos, los alcances y los límites del estudio, la permanencia en la investigación, el anonimato y la confidencialidad de la información suministrada. 


\section{Resultados}

\section{Hábitos de consumo televisivo de niños y padres}

Los hábitos de consumo televisivo de niños y padres responden a diversos aspectos, entre ellos la formación académica de los padres, la estructura familiar y las prácticas que han establecido en el día a día, de ahí la importancia de exponer una breve contextualización de las familias que participaron en la investigación. Según se pudo establecer a partir de los datos relativos al nivel de educación formal, las madres de familia tienen mayor nivel de educación que los padres, lo cual expresa una tendencia muy característica de las tres últimas décadas en Colombia y América Latina en cuanto al incremento y mayor posicionamiento de las mujeres en ámbitos de la sociedad y la cultura urbana debido a su mayor cualificación profesional. Este hallazgo supone una mejor capacitación de las madres como agentes educativos de sus hijos. Como lo han constatado estudios acerca de la familia colombiana (Gutiérrez, 1994, pp. 27-49), desde la década de 1970 se ha presentado una menor disposición de las mujeres a tener hijos, dato que se corresponde con los resultados de esta investigación, pues $39.5 \%$ de los padres encuestados reporta tener al menos dos hijos y $24.7 \%$ un hijo único. Esta situación expresa la tendencia de las familias antioqueñas a la reducción considerable de la cantidad de hijos, lo cual ha sido más evidente en las ciudades debido a que la cultura urbana ha significado mayores expectativas de realización para las mujeres, quienes al profesionalizarse están menos dispuestas a mantener los tradicionales roles que hacían equivalente el hecho de ser mujer, madre y esposa. Podría suponerse que ante la mayor cualificación educativa de las madres, y la reducción de la cantidad de hijos que implica una mayor valoración de los niños en los hogares y en la sociedad, existe una mayor capacidad de ellas para atenderlos y cuidarlos; sin embargo, las demandas del mundo laboral y de autorrealización profesional les ha impuesto restricciones en las tareas educativas en el hogar. Los niños de las familias indagadas viven predominantemente en hogares nucleares, pues $39.5 \%$ vive con sus padres y hermanos y $24.7 \%$ vive solo con sus padres en cuanto son hijos únicos. Solo $16.0 \%$ vive con la madre y $6.2 \%$ vive con abuelos. Estos datos revelan que, pese a las profundas transformaciones de la vida familiar en los últimos tiempos, sigue siendo 
la familia nuclear el modelo de mayor peso social. En cuanto a los hábitos de consumo televisivo, es preciso señalar, en primera instancia, que del total de los 81 padres encuestados $97.5 \%$ tiene televisión por cable en sus hogares ante $2.5 \%$ que solo cuenta con televisión abierta, dato que corrobora que la televisión por cable es un servicio privado, cuyo uso se ha generalizado a todos los estratos socioeconómicos en un área urbana caracterizada por su efectiva infraestructura de servicios públicos y la vertiginosa expansión de la conectividad. Otro factor que caracteriza a las familias encuestadas es que $70.4 \%$ de ellas tiene entre dos a cuatro televisores en casa, lo cual supone una generalización de la industria cultural por vía de la televisión y una tendencia muy propia de las familias urbanas contemporáneas a la "individualización de consumo televisivo", lo cual se sustenta en el hecho de que $51.9 \%$ de los niños, según sus padres, tiene televisor en su habitación. Si nos atenemos a los estudios realizados por la Academia Americana de Pediatría, este asunto reviste múltiples problemas en cuanto supone para un niño de tan corta edad una excesiva incitación a ver televisión y desplazar otras actividades fundamentales para su desarrollo integral, como aquellas que tienen que ver con el juego en cuanto promotor de la socialización primaria con sus pares y sus familias, el sueño, hábitos alimentarios adecuados y comportamientos prosociales (American Academy of Pediatrics, 2001). No obstante, llama la atención que el lugar donde los niños más suelen ver televisión es la habitación de los padres (39.5\%), lo cual posiblemente expresa la imperante necesidad afectiva de los niños pequeños por estar en compañía de ellos, mientras que $21.0 \%$ de los niños ve televisión en su propia habitación. Esta práctica de consumo televisivo suele hacerla el niño solo (35.8\%) seguido de aquellos que lo hacen en compañía de sus madres $(24.7 \%)$ y en compañía de sus hermanos $(21.0 \%)$. La prevalencia de los hijos que ven televisión solos y en compañía de sus hermanos (que con frecuencia tienen edades cercanas) en comparación con los que lo hacen con un adulto ( $42 \%$ ) es muy alta (supera el $50 \%$ ), lo cual indica que la mediación familiar es precaria. El consumo televisivo del niño en solitario es más acentuado en los estratos uno (52.4\%) y tres (54.5\%), mientras que quienes menos ven televisión solos son los niños de estrato seis $(10 \%)$, pues suelen estar acompañados por sus madres (30\%) y por sus hermanos (40\%). Estos indicadores, sumado al hecho de que $67.9 \%$ 
de los niños decide qué programa ver, parecen expresar el exiguo papel de los adultos en su alfabetización visual y en su papel como orientadores para incidir en la formación de criterios de consumo desde temprana edad. Este hallazgo es evidencia aparente de que la televisión por sí misma no tiene mucho poder, sino que su contundente irrupción y presencia en los hogares se debe al poder que le han concedido los adultos mismos al dejar que gran parte de sus niños instauren una relación directa con ella. Lo anterior no es para nada un avance en la autonomía de los niños como consumidores, sino la destitución de los adultos por sí mismos de su papel de educadores derivado de condiciones objetivas, como las demandas laborales (rigidez de horarios, sobrecarga laboral e inestabilidad económica) y los afanes propios de la vida urbana, que los desbordan de su rol familiar (hechos que fueron señalados en las entrevistas). Estos cambios de dinámicas propician que la familia, según Giddens, termine siendo una institución concha, pues la apariencia o concha exterior permanece pero por dentro ha cambiado y, por tanto, se ha vuelto inadecuada para las tareas que está llamada a cumplir (2000, p. 31).

Respecto del número de horas que los niños suelen ver televisión de lunes a viernes, según los padres, $48.1 \%$ lo hace de una a dos horas diarias, seguido de $29.6 \%$ que ve de dos a seis horas diarias, $6.2 \%$ de cuatro a seis horas diarias y $3.7 \%$ consume más de seis horas al día. De ello se colige que un significativo porcentaje ( $39.5 \%$ ) de los niños consume de dos a más de seis horas diarias, solo $12.3 \%$ consume menos de una hora diaria y el horario de mayor consumo ocurre entre las 5:00 y 8:00 p. m. Si analizamos el consumo de horas de televisión por día, los resultados revelan que los niños de los estratos uno, dos, cinco y seis ven un promedio de tres horas diarias, mientras que los de estratos tres y cuatro consumen un promedio de cuatro horas por día.

La indagación por los hábitos que tienen los padres de familia cuando ven televisión con sus niños señala que un porcentaje significativo de ellos tiene una actitud activa y dialógica, en cuanto afirman que conversan y opinan con los niños acerca de los contenidos televisivos. La intervención dialogada de los padres se hace más evidente cuando se trata de reforzar 
lo que enseñan a los niños y que aparece expuesto en los contenidos televisivos, como lo indica el hecho de que $46.9 \%$ de los padres lo haga siempre y $32.1 \%$ casi siempre. Este hábito pareciera estar dirigido a reforzar en el niño comportamientos, ideas y valores que sus padres han posicionado, con un tono prescriptivo en su vida cotidiana, y no necesariamente a que el niño reflexione y opine desde su propia perspectiva. Este hábito aparece confirmado por otro indicador que revela que la mayoría de los padres no suscita en sus hijos la reflexión mediante preguntas o cuestionamientos dirigidos a que el niño dilucide y someta los contenidos televisivos a la crítica, pues así lo manifiesta el hecho de que $38.3 \%$ pocas veces lo hace y $17.3 \%$ nunca lo realiza. Llama la atención que los padres de los estratos cinco y seis son los que menos propician la reflexión con sus hijos con porcentajes de $14.0 \%$ y $10.0 \%$, respectivamente, mientras que los de los estratos dos y tres son los que más desarrollan esta acción con 73 \% y $64 \%$, respectivamente. Ello indica que la acción reflexiva que se espera de un padre de familia frente al consumo televisivo no está condicionada per se por sus mayores niveles de bienestar y educación formal.

Además de lo señalado, se indagó sobre las acciones que realizan los padres cuando sus hijos están viendo programas con mensajes televisivos que consideran inadecuados para su formación. El 80.2\% afirma cambiar de canal o apagar el televisor dándole una explicación al niño, lo cual parece indicar que los padres no asumen actitudes autoritarias en esta situación, pues argumen$\tan y$ justifican sus intervenciones, por lo que se puede considerar que tales actos tienen una intención formativa. Como se puede apreciar, estos hallazgos dan cuenta del lugar de la familia y particularmente de los padres como agentes mediadores del consumo televisivo de sus niños, lo cual acontece en dos sentidos. El primero indica que los padres se posicionan como el filtro por el cual deben pasar los contenidos televisivos que han de llegar a sus hijos, lo cual implica someterlos a una especie de trabajo interpretativo unidireccional, toda vez que son ellos quienes identifican y decodifican los textos televisivos en función de sus parámetros valorativos e intentan direccionarlos a sus hijos sin contar con su deliberada participación. Si bien el hecho de que los padres acompañen a sus hijos ha sido valorado por teóricos de la recepción (Orozco, 1991; López de la Roche, Martín-Barbero, Rueda, 
Valencia, 2000; Fuenzalida, 2005) como la mediación inicial en el consumo televisivo de los niños, los anteriores hallazgos muestran que esta tiene un claro corte regulador y normativo, pues se asume al niño como un sujeto sin capacidades cognitivas y morales y tampoco se propicia la formación de estas competencias para hacer de ellos receptores críticos. El segundo es consecuencia relativa del primero, pues el hecho de que el niño vea televisión en compañía de sus padres constituye una práctica de las relaciones de autoridad que establece el padre con sus hijos, en cuanto aquel está allí para desplegar su poder orientador y sancionador de lo que se ve y se dice.

\section{Representaciones de autoridad agenciadas por la televisión}

Es de aclarar que las representaciones de que dan cuenta los padres desde su consumo televisivo (ya sea solos, ya sea en compañía de sus hijos) no se indagaron en relación con un programa en particular, sino desde las experiencias mediáticas más generales que acontecieron en su vida cotidiana para el momento en que se recolectó la información, es decir, para el primer semestre de 2013. Tal pesquisa se realizó en torno a diversas subcategorías. En relación con la subcategoría de “autoridad y normas”, $39.5 \%$ de los padres encuestados considera que pocas veces en los programas que ellos ven los padres aparecen imponiendo las normas a los hijos sin contar con su opinión, de igual forma el $27.2 \%$ considera que este hecho nunca sucede en los programas. Ello parece indicar que los padres que se muestran en la televisión asumen conductas menos autoritarias con sus hijos y promueven su participación en la concertación de las normas de la vida familiar. Este acercamiento hacia los hijos de los padres que presenta la televisión se ve acompañado del deseo de ser amigos de ellos, pues $22.2 \%$ y $32.1 \%$ de los encuestados afirma ver siempre o casi siempre, respectivamente, que esto sucede en los programas de televisión. Preguntados los padres acerca de si en los programas de televisión se presentan niños acatando las normas familiares sin discutirlas, $60.5 \%$ respondió que pocas veces y $14.8 \%$ que nunca ve tal situación. Los anteriores hallazgos sugieren que los programas de televisión agencian relaciones más simétricas entre padres e hijos y abogan por la participación de los niños en la definición de normas del régimen familiar, fenómeno que ha sido abordado por Elías (1998, p. 412), 
quien reconoce relaciones menos autoritarias y más igualitarias en las sociedades modernas entre padres e hijos. El $74.3 \%$ de los encuestados refiere que los niños que muestra la televisión cumplen las normas por causas externas, como la amenaza de castigo, y no por la conciencia o convencimiento de la necesidad de obedecerlas, es decir, por lo que representan en sí mismas. Esta naturaleza netamente coactiva de la norma asumida así por niños ha sido referida como propia y adecuada al desarrollo moral del niño de la edad de menos de 6 años (Piaget, 1971; Kolhberg; 1997). Acerca de la subcategoría "autoridad y estrategias de corrección”, los padres encuestados consideran que pocas veces (34.6\%) y nunca (40.7\%) se evidencia que en la televisión los padres corrijan a los niños mediante el castigo físico, al contrario, perciben que casi siempre (46.9\%) y siempre (7.4\%) tienden a corregir mediante el diálogo y la reflexión. Estos hallazgos indican que la televisión expresa mutaciones producidas en la sociedad contemporánea al desplazar la fuerza y la violencia, que fueron usuales en la familia patriarcal hasta hace una décadas tanto en Colombia como en la región antioqueña (Gutiérrez de Pineda, 1994, p. 30), por métodos más moderados, a fin de orientar a sus hijos; situación que también se ve expresada en el hecho de que los padres en la televisión tienden a corregir a los niños quitándoles privilegios siempre $(13.6 \%)$ o casi siempre $(45.7 \%)$. Es de resaltar que $44.4 \%$ y $13.6 \%$ de los padres consideran que pocas veces y nunca, respectivamente, se muestra en los programas de televisión padres haciéndose los desentendidos para no castigar a los hijos. Este último dato parece indicar que los padres en la televisión son representados como sujetos que tienen autoridad ante su prole y la hacen manifiesta a la hora de sancionarlos. Tal hallazgo se constata con el hecho de que $40.7 \%$ y $13.6 \%$ de los encuestados considera que pocas veces o nunca, respectivamente, los progenitores que presenta la televisión no saben cómo corregir a sus propios hijos. De lo anterior se desprende que la televisión parece agenciar una representación de padres conscientes de su lugar como figuras de autoridad y que tienen claras las formas más adecuadas para relacionarse con sus hijos en este aspecto, lo cual desvirtúa parcialmente la idea de que en los contenidos televisivos los padres aparecen destituidos de autoridad.

En relación con la subcategoría "autoridad y género", los padres televidentes afirman que pocas veces $(35.8 \%)$ y nunca $(18.5 \%)$ sus homó- 
logos de los programas televisivos aplican diferente la autoridad según se trate de niño o niña. No obstante, parece que los niños que muestra la televisión sí responden de forma diferente al reconocimiento de la autoridad si esta deriva del padre o de la madre, pues los encuestados afirman que así sucede, casi siempre $45.7 \%$ y siempre $17.3 \%$, con especial tendencia a obedecer más a padres que a madres. La igualación de los géneros se hace relativa al indagar sobre la disposición de niñas y niños a obedecer a sus padres, pues según los encuestados las niñas que muestra la televisión están más dispuestas que los niños a obedecer: siempre $8.6 \%$ y casi siempre $43.2 \%$.

Respecto de la subcategoría “autoridad y géneros televisivos", los padres televidentes expresan que los programas infantiles parecen apropiados para sus niños, pues $67.9 \%$ opina estar en parte de acuerdo y $25.9 \%$ totalmente de acuerdo con los mensajes acerca de las relaciones de autoridad que allí se exponen. Si consideramos que este es el género más visto por los niños, y que en su diseño y creación interviene un amplio grupo de profesionales de diversas disciplinas conocedores del mundo infantil, podría esperarse una mayor satisfacción de los padres respecto de los contenidos que este tipo de programas presenta. No sucede así, lo que posiblemente es indicio de que este género no les ofrece a los padres los ideales de interacción familiar que esperan. Llama la atención que existe una alta coincidencia entre los programas preferidos por los niños, según sus padres, y los que los mismos niños expresan ser de su mayor preferencia. Es de destacar que, a pesar de que los niños son quienes eligen los programas que desean ver, y que los consumen en la mayoría de las ocasiones sin la compañía de un adulto, los padres tienen un pleno conocimiento de las preferencias televisivas de sus hijos. Este dato, según se corroboró en los grupos focales y en los talleres con los niños, da cuenta de los acuerdos que previamente hacen los padres con sus hijos acerca de la parrilla televisiva permitida y del respeto y sujeción de los niños a tales convenios.

Los noticieros tienden a estar en el extremo opuesto de los programas infantiles, pues casi la mitad de los encuestados (46.9\%) rechaza totalmente sus contenidos atinentes a las relaciones de autoridad que presentan; sin embargo, $40.7 \%$ de los padres dice estar en parte de acuerdo con estos, lo 
cual no es una tendencia por desestimar. Los hallazgos permiten afirmar que el rechazo a los noticieros se afinca en su carácter realista y en la reiterada presentación de contenidos violentos. En cuanto a las telenovelas, se asiste a un panorama valorativo muy distinto del de hace unas décadas cuando la familia colombiana y particularmente mujeres y niños eran asiduos consumidores de este género (Martín-Barbero y Muñoz, 1992). En la actualidad, más de la mitad de los padres encuestados (51.9\%) rechaza totalmente los contenidos de las telenovelas y $34.6 \%$ dice estar en parte de acuerdo con ellas. La notoria resistencia a las telenovelas deriva de la creciente industria de narconovelas (Rincón, 2010), con lo que se ha filtrado el mundo de la violencia al mundo doméstico y la autoridad ha quedado representada por figuras del crimen y del delito global frente a un Estado débil y corrupto. Por otro lado, el desplazamiento de las telenovelas se explica por la ampliación de la oferta televisiva sobre todo a través de la televisión cerrada y la emergencia de nuevos géneros muy aceptados por parte de la familia.

Junto con los programas infantiles, los documentales científicos son el género más valorado por los encuestados en asuntos relativos a la vida familiar y en particular a los atinentes a las relaciones de autoridad. ${ }^{5}$ Este género ha logrado amplia difusión en la televisión cerrada y cuenta con una extensa participación de ciencias y disciplinas, como la biología, la psicología, la medicina, la pedagogía y la historia, cuyos hallazgos han sido traducidos a narrativas visuales y de difusión con miras a su socialización; por ello, cuentan con una teleaudiencia muy variada de todos los niveles socioculturales. Así lo revela el hecho de que $54.3 \%$ de los encuestados está totalmente de acuerdo con sus contenidos, sumado a $32.1 \%$ que dice estar en parte de acuerdo.

La autoridad y el contexto sociocultural fue otra de las subcategorías indagadas. Si bien la pesquisa estuvo referida al ámbito familiar, la sociología ha dejado claro que la familia no es una figura autónoma de la socie-

5 Cabe anotar que los deportes también gozan de una amplia aceptación entre los padres, pues $42 \%$ manifiesta estar en parte de acuerdo y $25.9 \%$ totalmente de acuerdo con sus mensajes. Para un porcentaje considerable (28.4\%), este género le es indiferente. La aceptación de los deportes entre los padres se explica a partir de algo que resulta propio del deporte mismo, y es la necesaria presencia de reglas representadas por jueces y árbitros, la orientación al logro, la competencia, los premios y las sanciones, la cooperación y la autorregulación de los sujetos. 
dad, pues, a la vez que dispone formas de estructuración social, ella misma está condicionada social y culturalmente. En un país de culturas regionales que han marcado profundamente el devenir nacional, no es arbitrario indagar sobre la forma como las familias configuran las relaciones de poder y de autoridad. Los encuestados no son indiferentes al asunto, pues, al ser interrogados acerca de la forma como la televisión presenta distintas maneras de ejercer la autoridad según culturas de las regiones de pertenencia de las familias, $21 \%$ considera que siempre y $44.4 \%$ que casi siempre se da esta situación.

La diferenciación social en Colombia por estratos socioeconómicos responde a lógicas político-administrativas que expresan la heterogeneidad de los contextos socioculturales en que acontece el diario vivir de las familias. Sobre este asunto se interrogó a los padres en cuanto a si la televisión presenta distintas formas de ejercer la autoridad según el estrato socioeconómico, a lo cual $24.7 \%$ respondió que siempre y $49.4 \%$ que casi siempre. Es claro que las familias colombianas acceden a la educación, la vivienda, el trabajo y a mejores condiciones de vida dependiendo de las oportunidades sociales y económicas que han configurado su lugar en la sociedad. Los ámbitos socioculturales más inmediatos a las familias suelen tener una mayor incidencia en la forma como los padres ejercen la autoridad con sus hijos, sobre todo en una sociedad como la antioqueña, cuyas tradiciones católicas y campesinas han generado formas de cohesión social de hondo arraigo en las comunidades barriales con inveteradas prácticas de patriarcalismo.

En las últimas décadas, se asiste a una vida citadina donde las familias y barrios han estado sometidos a agresivos procesos de urbanización, violencia y fragmentación social, con lo cual se han debilitado viejos referentes de solidaridad, cohesión y prácticas cívicas heredadas del ethos comunitario pueblerino. La producción televisiva logra leer estos contextos y en este sentido en la investigación se ha indagado por la forma como en los programas de televisión cada familia ejerce la autoridad según sus propios criterios sin depender de lo que consideran sus vecinos, figuras sociales, como el cura del barrio, el maestro y aun funcionarios públicos responsables de la gestión del bienestar infantil. Al respecto, la mayoría de los interrogados, 
$59.2 \%$ respondió que siempre percibe en la televisión un ejercicio de la autoridad de las familias solo a partir de sus propios criterios, es decir, al margen de regulaciones sociales. Esta percepción se encuentra con mayor énfasis en los estratos dos y seis, con $73.3 \%$ y $70 \%$, respectivamente, mientras que los estratos cuatro y cinco son los que menos la representan, con $41.2 \%$ y $42.9 \%$, respectivamente. Este tipo de indicadores pareciera señalar que los padres reconocen un régimen familiar que se debe a sus propias lógicas y que la autoridad se circunscribe al mundo de lo privado, aun en sectores populares en los que se ha asumido que la soberanía familiar ha estado más permeada por las lógicas de una familia extendida, la vida comunitaria y barrial.

Existen indicios de que la autonomía de las familias para el ejercicio de autoridad con sus hijos ha venido focalizándose en los propios padres, lo cual ha supuesto un desplazamiento de figuras que antaño tenían gran incidencia en la definición del régimen familiar, como lo eran abuelos y tíos como expresión de familias ampliadas muy comunes. De ahí que se haya preguntado por esta situación y por la forma como la televisión la ha publicitado. Según los datos, 37 \% de los encuestados considera que casi siempre en la televisión los mayores de familia, como abuelos y tíos, ya no son figuras de autoridad para los niños, mientras que un porcentaje igual de padres opina que ello ocurre pocas veces.

Así como interesa indagar sobre las figuras que representan poder y autoridad en las familias, es pertinente explorar la forma como la autoridad se perfila en figuras públicas, lo cual constituye un punto de vista privilegiado para comprender la manera como la familia se representa y articula a las estructuras sociales y cómo dispone la institucionalidad con sus lógicas de legitimidad, consenso y reconocimiento. La indagación acerca de este tópico se realizó mediante una escala de valoración de uno a diez, en la que los padres encuestados debían organizar en orden descendente a diferentes personajes públicos, donde uno correspondía al que con más autoridad se presentara en la televisión, y con un valor de diez a quien se presentara con menor autoridad. Las figuras públicas fueron elegidas en el entendido de que representan la institucionalidad en sus distintos ámbitos 
sociales, económicos, políticos y culturales de la vida nacional. Así, para el Estado se escogieron los políticos, jueces y policías; de la Iglesia católica, a los sacerdotes; representativos de la institución escolar y del mundo científico, a maestros y científicos; de los medios de comunicación, a personajes emblemáticos; del mundo económico, al empresario; de la cultura y la recreación, a los deportistas, y otros integrantes de la sociedad de gran visibilidad televisiva y que ponen en juego relaciones de poder y normas sociales, como jefes de bandas, guerrilleros y narcotraficantes. Para fines del análisis se establecieron tres rangos de valoración de la siguiente manera: el primero para las figuras públicas clasificadas por los encuestados en los valores de uno a tres, es decir, aquellos presentados en la televisión como las figuras de mayor autoridad; el segundo, para las figuras clasificadas en los valores de ocho a diez, es decir, aquellas que para los encuestados aparecen en la televisión con menor autoridad; y un tercer rango, para las figuras públicas ubicadas en los valores de cuatro a siete, es decir, aquellos cuyos puntajes se ubicaron con valores medios. En el primer rango de las figuras sociales presentadas en la televisión que son percibidas por los padres como las de mayor autoridad, aparecen en su orden los jefes de bandas, guerrilleros y narcotraficantes con un consolidado de $71.6 \%$, seguido de los políticos con $60.4 \%$ y los policías con $34.6 \%$. Discriminados por estratos socioeconómicos, se tiene que el seis es el que más reconoce que en la televisión los políticos figuran como sujetos con gran autoridad, con $70 \%$ de los encuestados, y los que menos los reconocen de esta forma son los padres del estrato cinco, con $42.9 \%$. Valga destacar que los padres de familia del estrato dos son quienes más identifican que la televisión presenta a los policías con gran autoridad, con $50 \%$, mientras que ninguno $(0.0 \%)$ de los padres del estrato cinco considera que la televisión presenta a los policías como figuras de autoridad.

Acerca de la imagen de autoridad que muestra la televisión respecto de los capos de la mafia, guerrilleros y jefes de bandas delincuenciales, se identifica que son los padres de los estratos cuatro y cinco quienes más los ven en televisión como figuras de autoridad con $94.1 \%$ y $85.7 \%$, respectivamente, mientras que los padres de estratos dos y seis son quienes menos los ven de esta forma, con un porcentaje de igual valor, $60 \%$. Todo parece 
indicar que no existen condicionamientos socioeconómicos para el reconocimiento de la autoridad en estas figuras desde la televisión.

En el extremo opuesto (segundo rango) de las figuras que presenta la televisión con menor autoridad, a juicio de los padres, están en su orden los científicos, con un consolidado de $54.3 \%$, seguido de personajes de medios de comunicación con $46.8 \%$, y en tercer lugar los deportistas con $38.2 \%$. Al discriminar por estratos socioeconómicos, se tiene que los estratos cuatro y seis son los que menos ven en ellos figuras de autoridad desde su consumo televisivo con $64.7 \%$ y $60 \%$, respectivamente.

Comprender estos indicadores cuantitativos implica reconocer que, desde la década de 1980 en la vida nacional y en la televisión en particular, personajes del mundo delincuencial han tenido gran visibilidad pública y protagonizado la proliferación de las violencias (partidista, guerrillera, paramilitar, mafiosa y delincuencia común), la emergencia de contra-poderes y para-poderes estatales, nuevas formas de legitimarse y de crear lealtades y estructuras de dominio y de organización social. Ha sido tal el posicionamiento de estas figuras públicas en un país dividido y en una sociedad fragmentada, en una Colombia donde predomina una "cultura de la ilegalidad", que definitivamente ello ha supuesto la legitimación de una ética de los fines que justifica apelar a cualquier medio para lograr los cometidos de los sujetos. Los historiadores Palacios y Safford (2002, pp. 326-328) dan cuenta de la presencia, desde hace tres décadas, de la corrupción de políticos, la anomia de los pobres, el desencanto político de las clases medias y la expansión vertiginosa del delito, conjugación, que según ellos, ha provocado el sentimiento tan común en la década de 1990 de vivir el "derrumbe" del país por cuenta de la notoria expansión de la criminalidad organizada con un alto poder de corrupción de las instituciones y un Estado que se ha mostrado impotente para frenarla. Tales problemáticas han sido ampliamente visibilizadas por la televisión a la par que se han presentado imágenes de la familia, la escuela y la Iglesia católica como instituciones débiles que han perdido reconocimiento social. Congruentemente con ello, los policías, narcotraficantes, insurgentes y hasta los políticos han sido mostrados por la televisión, y particularmente por los noticieros, con narrativas que perfilan 
su alto grado de ilegalidad e ilegitimidad; sin embargo, y paradójicamente, la mayoría de los padres encuestados perciben que la televisión los presenta como figuras con gran autoridad. Una posible explicación para esta ambigua situación tiene que ver con la superposición de significaciones que suele darse entre dos conceptos, como son 'autoridad' y 'poder'. Recordemos que el primero contiene al segundo, es decir, la autoridad para que se revista de tal no puede hacer uso de la coacción ni de la violencia e implica una subordinación voluntaria a quien se reconoce prestigio y estatus moral (Arendt, 2003, p. 102), mientras que el poder puede estar recubierto de grados de violencia y coacción y asegura su existencia mediante la obligatoria subordinación, esta deja de ser opcional y acontece como consecuencia ante cualquier tipo de poder, sea económico, simbólico, físico, social o jurídico. No sobra recordar que en el rango medio (tercer rango) se ubican las figuras públicas que obtuvieron valores en la escala de cuatro a siete, es decir, aquellas cuyos puntajes oscilaban entre los valores extremos, siendo en su orden: sacerdotes, empresarios, maestros y jueces. Llama la atención el hecho de que los maestros y sacerdotes, figuras históricas fundantes de las relaciones de autoridad en la sociedad colombiana, estén ubicados en este rango valorativo que manifiesta su evidente pérdida de prestigio y poder regulador. Respecto de los jueces, y a pesar de los esfuerzos de la clase dirigente a partir de la Constitución de 1991 por fortalecer y modernizar las instituciones del Estado, es llamativo que el ciudadano del común, en este caso los padres de familia, perciban todavía la débil institucionalidad de la rama judicial, la que representa la operatividad del cumplimiento de las normas y las sanciones legales. De forma similar a la autoridad moral que asiste a maestros y sacerdotes, y a la autoridad legal que inviste a los jueces, el poder económico de los empresarios, bien difundido por la televisión bajo la imperante tendencia neoliberal, no se traduce en un preponderante sino en un moderado reconocimiento como figuras de autoridad.

\section{Conclusiones}

Después de la trama de relaciones y problemas expuestos es posible constatar, como lo han señalado diversos autores (Orozco, 1991; Silverstone, 1996; Martín-Barbero, 2006), que la cotidianidad familiar es el espacio de las relaciones más próximas que constituyen la recepción televisiva, con lo 
cual esta dispone y organiza el tiempo y los espacios de quienes la habitan y trae sus propias tramas culturales a la vida doméstica. Los hallazgos indican que los padres y sus niños consumen la televisión desde los diversos géneros que la caracterizan, lo cual se ubica en la misma dirección de lo afirmado por Renero (1992) y Martín-Barbero (2006) en el sentido de que no se ve televisión en abstracto, sino a partir de la amplia gama de los géneros que la constituyen, más aún cuando la totalidad de los padres encuestados accede a la televisión cerrada. No sobra hacer hincapié en que el consolidado de información analizada muestra que, según los padres encuestados, su consumo televisivo y el de sus hijos, se extiende a una muy variada parrilla que involucra desde los más tradicionales géneros, como telenovelas, noticieros, musicales, infantiles, deportivos, documentales, hasta el más reciente llamado reality show. La generalización de la televisión cerrada en todos los estratos socieconómicos ha traído consigo un consumo más individualizado del medio aun por parte de los niños más pequeños de la muestra indagada; no obstante, los padres ejercen control sobre la parrilla televisiva vista por sus hijos. La incorporación de mensajes televisivos por parte de los padres acontece al mismo tiempo que otros son objeto de rechazo y resistencia en cuanto se valoran como inconvenientes e inapropiados para la orientación de sus hijos acerca de las relaciones de autoridad. Ello es evidencia del posicionamiento de los padres como televidentes hermeneutas que no se pliegan a los mensajes televisivos, lo cual desvirtúa la lectura ideologizante de los medios. Por último, en cuanto a la recepción de los padres de las representaciones de autoridad agenciadas por la televisión, se deduce que en este medio se presentan relaciones más simétricas entre padres e hijos y mayor participación de los últimos en la definición de normas y decisiones familiares. Instituciones tradicionales como la familia, la Iglesia, la escuela y el Estado se presentan en la televisión con un notorio declive de su autoridad y un destacado ascenso del poder de figuras que actúan al margen de la ley, como capos de la mafia, jefes de bandas y guerrilleros, lo cual, según los padres, influye negativamente en las percepciones de los niños sobre la autoridad.

Los anteriores hallazgos justifican la realización de propuestas educativas con padres de familia, maestros y adultos significativos de los niños 
en cuanto son los primeros socializadores y referentes para la construcción de la noción de 'autoridad'. Asimismo, son los principales mediadores del consumo televisivo de los niños y de la formación de su juicio crítico como televidentes. De igual forma, es necesario involucrar a los productores de los contenidos televisivos en procesos reflexivos que les permitan la toma de conciencia acerca de su lugar en la construcción de una cultura de la legalidad en Colombia.

\section{Referencias}

American Academy of Pediatrics. (2001). American Academy of Pediatrics: Children, adolescents, and television. Pediatrics, 107(2), 423.

Arendt, H. (2003). Entre el pasado y el futuro: ocho ejercicios sobre la reflexión política. Barcelona: Península.

Consejo Nacional de Televisión de Chile (2011). Los padres y la regulación televisiva. Recuperado el 13 de mayo de 2015 de http: / / www.comunicainfancia.cl/wp-content/uploads/2012/04/Padresymadres.pdf

De Oliveira Zacarias, M. C. (2005). Família e TV: mais que dominação e subordinação (Tesis doctoral, Universidade Federal do Rio Grande do Norte, Brasil).

Elías, N. (1998). La civilización de los padres. En La civilización de los padres y otros ensayos (pp. 407-450). Bogotá: Norma.

Fuenzalida, V. (2005). Expectativas educativas de las audiencias televisivas. Bogotá: Norma.

García Canclini, N. (2006). El consumo cultural: una propuesta teórica. En G. Sunkel (coord.), Consumo cultural en América Latina (pp. 72 95). Bogotá: Convenio Andrés Bello.

Giddens, A. (2000). Un mundo desbocado: los efectos de la globalización en nuestras vidas. Madrid: Taurus. 
Giddens, A. (2003). La constitución de la sociedad: bases para la teoría de la estructuración. Buenos Aires: Amorrortu.

Gutiérrez de Pineda, V. (1994, 19-22 de abril). Año Internacional de la Familia: familia colombiana. En Memorias del Congreso Latinoamericano de Familia: Siglo XXI. Medellín.

Kohlberg, L. (1997). La educación moral. Barcelona: Gedisa.

López de la Roche, F., Martín-Barbero, J., Rueda, A. y Valencia, S. (2000). Los niños como audiencias: investigación sobre recepción de medios. Bogotá: Instituto Colombiano de Bienestar Familiar.

Martín-Barbero,J. y Muñoz, S. (1992). Televisión y melodrama: géneros y lecturas de la telenovela en Colombia. Bogotá: Tercer Mundo.

Martín-Barbero, J. (2006). Recepción de medios y consumo cultural: travesías. En G. Sunkel, El consumo cultural en América Latina (pp. 47-71). Bogotá: Convenio Andrés Bello.

Ministerio de Cultura/Dirección de Cinematografía (2009). Análisis exploratorio sobre nuevas identidades infantiles y su relación con los medios audiovisuales de comunicación. Bogotá: Ministerio de Cultura/Dirección de Cinematografía. Recuperado de http:// www.mincultura.gov.co $/$ ?idcategoria $=38491 \&$ download $=Y$

Orozco Gómez, G. (1991). Mediaciones familiares y escolares en la recepción televisiva de los niños. Intercom: Revista Brasileira de Ciências da Comunicação, 14(64), 8-19.

Palacios, M., y Safford, F. (2002). Colombia: país fragmentado, sociedad dividida. Su historia. Bogotá: Norma.

Piaget, J. (1971). El criterio moral en el niño. Barcelona: Fontanella. 
Renero, M. (1992). De géneros televisivos y usos familiares. Comunicación y Sociedad, 14-15, 19-38.

Rincón, O. (2010). NarcoTv: o lo narco como marca actual de la telenovela colombiana. Quimera: Revista de literatura, 315, 41-4.

Rodríguez, A. (2012). Los niños menores de tres años y la televisión: perspectivas de investigación y debate 1999-2010. Bogotá: Ministerio de Cultura.

Torrecillas Lacave, T. (2012). La interacción padres e hijos en el contexto televisivo infantil: estrategias de alfabetización mediática en el hogar. Doxa Comunicación: Revista Interdisciplinar de Estudios de Comunicación y Ciencias Sociales, 15, 175-194.

Silverstone, R. (1996). Televisión y vida cotidiana. Buenos Aires: Amorrortu.

Silverstone, R. (2004). ¿Por qué estudiar los medios? Buenos Aires: Amorrortu. 